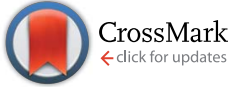

Cite this: Chem. Sci., 2014, 5, 3501

\title{
Rules for priming and inhibition of glycosaminoglycan biosynthesis; probing the $\beta 4$ GalT7 active site $\uparrow$
}

\author{
Anna Siegbahn, ${ }^{a}$ Sophie Manner, $\dot{t}^{\mathrm{a}}$ Andrea Persson, $\dot{t}^{\mathrm{ab}}$ Emil Tykesson, $\dot{t}^{\mathrm{b}}$ \\ Karin Holmqvist, ${ }^{a}$ Agata Ochocinska, ${ }^{a}$ Jerk Rönnols, ${ }^{c}$ Anders Sundin, ${ }^{a}$ Katrin Mani, ${ }^{b}$ \\ Gunilla Westergren-Thorsson, ${ }^{\mathrm{b}}$ Göran Widmalm ${ }^{\mathrm{c}}$ and Ulf Ellervik ${ }^{\star a}$
}

$\beta-1,4-$ Galactosyltransferase 7 ( $\beta 4$ GalT7) is an essential enzyme in the biosynthesis of glycosaminoglycan (GAG) chains of proteoglycans (PGs). Mammalian cells produce PGs, which are involved in biological processes such as cell growth and differentiation. The PGs consist of a core protein, with one or several GAG chains attached. Both the structure of the PGs and the GAG chains, and the expression of the enzymes involved in their biosynthesis and degradation, vary between normal cells and tumor cells. The biosynthesis of GAG chains is initiated by xylosylation of a serine residue of the core protein, followed by galactosylation by $\beta 4$ GalT7. The biosynthesis can also be initiated by exogenously added $\beta$-Dxylopyranosides with hydrophobic aglycons, which thus can act as acceptor substrates for $\beta 4$ GalT7. To determine the structural requirements for $\beta 4$ GalT7 activity, we have cloned and expressed the enzyme and designed a focused library of 2-naphthyl $\beta$-D-xylopyranosides with modifications of the xylose moiety. Based on enzymatic studies, that is galactosylation and its inhibition, conformational analysis and molecular modeling using the crystal structure, we propose that the binding pocket of $\beta 4 G$ alT7 is very narrow, with a precise set of important hydrogen bonds. Xylose appears to be the optimal acceptor substrate for galactosylation by $\beta 4$ GalT7. However, we show that modifications of the xylose moiety of the $\beta$-D-xylopyranosides can render inhibitors of galactosylation. Such compounds will be valuable tools for the exploration of GAG and PG biosynthesis and a starting point for development of anti-tumor agents.

Received 30th April 2014 Accepted 11th June 2014

DOI: $10.1039 / \mathrm{c} 4 \mathrm{sc} 01244 \mathrm{e}$

www.rsc.org/chemicalscience

\section{Introduction}

$\beta$-1,4-Galactosyltransferase 7 ( $\beta 4 \mathrm{GalT} 7)$ is a key enzyme in the biosynthesis of heparan sulfate (HS) and chondroitin sulfate/ dermatan sulfate (CS/DS) glycosaminoglycan (GAG) chains. The GAG chains are linear polysaccharides of alternating uronic acids and aminosugars, which are most often linked to a core protein to form proteoglycans (PGs). PGs interact with growth factors and are important for a diverse set of biological processes, such as cell growth and differentiation. In addition, the PG/GAG expression is critical in the pathobiology of all stages of cancer progression, such as proliferation, tumor

${ }^{a}$ Centre for Analysis and Synthesis, Centre for Chemistry and Chemical Engineering, Lund University, P.O. Box 124, SE-22100 Lund, Sweden. E-mail: ulf.ellervik@chem. lu.se

${ }^{b}$ Department of Experimental Medical Science, Lund University, BMC A13, SE-221 00 Lund, Sweden

'Department of Organic Chemistry, Arrhenius Laboratory, Stockholm University, SE10691 Stockholm, Sweden

$\dagger$ Electronic supplementary information (ESI) available: Experimental parts for configurational and conformational analysis, biological testing, and synthesis. See DOI: $10.1039 / \mathrm{c} 4 \mathrm{sc} 01244 \mathrm{e}$

$\ddagger$ These authors contributed equally. invasion, and metastasis. ${ }^{\mathbf{1 - 3}}$ Both the structure of the PGs and the GAG chains, and the expression of enzymes involved in their biosynthesis and degradation vary between normal cells and tumor cells. For example, Sasisekharan and co-workers successfully used GAG fragments, released from tumor cell surfaces, to inhibit tumor growth and colonization in vivo. ${ }^{4}$ The enzymes involved in the biosynthesis of GAG chains are thus promising targets for drug development.

The biosynthesis of HS and CS/DS is initiated by xylosylation of a serine residue of the core protein by xylosyltransferase (XT). ${ }^{5}$ The xylosylated protein is then galactosylated in a stepwise manner by two galactosyltransferases ( $\beta 4 \mathrm{GalT7}$, also known as GalTI, ${ }^{6}$ and $\beta 3$ GalT6, also known as GalTII) and subsequently glucuronated by glucuronyltransferase I (GlcAT-I) to form a linker tetrasaccharide that is the branching point for the biosynthesis of HS and CS/DS (Fig. 1a). During the polymerization of HS and CS/DS, posttranslational modifications, such as $\mathrm{O}-$ and $\mathrm{N}$-sulfation, result in extensive structural diversity of the chains.

The biosynthesis of GAG chains can also be initiated by xylosides carrying hydrophobic aglycons, such as 2-naphthyl $\beta$-D-xylopyranoside (XylNap, 1a, Fig. 1b and Chart 1). ${ }^{7,8}$ The xylosides can, when exogenously supplied to cells, act as 


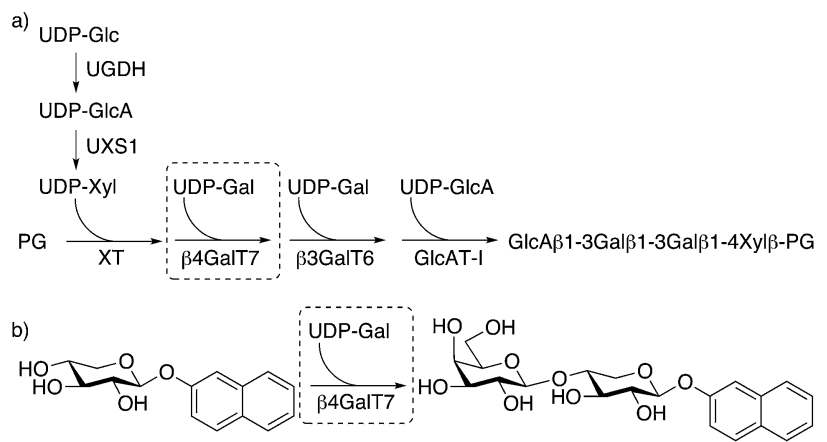

Fig. 1 (a) Biosynthesis of the linker tetrasaccharide of HS and CS/DS proteoglycans. (b) Galactosylation of XyINap to form GalXyINap.

acceptors in the first galactosylation step by $\beta 4 \mathrm{GalT} 7$, and thus provide a simplified model system for GAG biosynthesis, and serve as a starting point for development of anti-tumor drugs.

Up until the cloning of $\beta 4 \mathrm{GalT} 7$, the exploration of the biosynthesis of GAG chains has been limited to synthesis and testing of xylosides and xyloside analogs in cell assays. These studies have established the structural importance of the aglycon for the amount of GAG priming as well as for the type of chain primed (i.e., HS or CS/DS). ${ }^{9-18}$ Much less is known regarding modifications of the xylose moiety. In 2011, we reported the synthesis of a series of modified 2-naphthyl $\beta$-Dxylopyranosides, where each hydroxyl group was epimerized or replaced by a hydrogen atom, a fluorine atom, or a methoxy group (Chart 1, compounds $\mathbf{2 c - f}, \mathbf{3 c - f}$, and $\mathbf{4 c - f}$ ). ${ }^{19}$ The amount of GAG priming induced on these compounds was investigated and showed that treatment with XylNap initiated the expected priming of GAG chains, whereas none of the tested analogs showed priming of GAG chains. However, we observed a small inhibitory effect on the endogenous glycosylation of PG for the 4-fluoro and the 4-deoxy analogs (4d, 33\%, 4e, 24\%). These results were in accordance with findings from Kuberan and coworkers, who presented GAG inhibitors based on 4-deoxy-4fluoro-xylopyranosides with up to $90 \%$ inhibition. ${ }^{20,21}$ However, some of our results were contradictory to earlier investigations by Esko and co-workers who reported GAG priming by xyloside

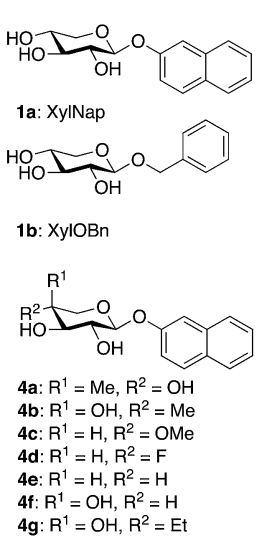

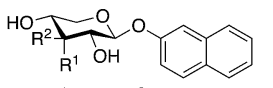

3a: $R^{1}=\mathrm{Me}, \mathrm{R}^{2}=\mathrm{OH}$ 3b: $\mathrm{R}^{1}=\mathrm{OH}, \mathrm{R}^{2}=\mathrm{Me}$ 3c: $R^{1}=H, R^{2}=O M e$ 3d: $R^{1}=H, R^{2}=F$ 3e: $R^{1}=H, R^{2}=H$ 3f: $R^{1}=O H, R^{2}=H$ 2f: $R^{1}=O H, R^{2}=H$

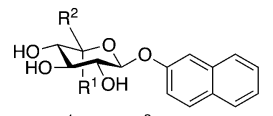

5a: $R^{1}=M e, R^{2}=H$ 5b: $R^{1}=\mathrm{H}, R^{2}=\mathrm{Me}$ 5c: $R^{1}=\mathrm{H}, \mathrm{R}^{2}=\mathrm{CH}_{2} \mathrm{OH}$ 5d: $R^{1}=H, R^{2}=\mathrm{COOH}$

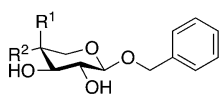

6a: $\mathrm{R}^{1}=\mathrm{Me}, \mathrm{R}^{2}=\mathrm{OH}$ 6b: $\mathrm{R}^{1}=\mathrm{OH}, \mathrm{R}^{2}=\mathrm{Me}$ 6c: $R^{1}=H, R^{2}=O M e$ 6d: $R^{1}=H, R^{2}=H$ 6e: $R^{1}=O H, R^{2}=H$ 6e: $R^{1}=O H, R^{2}=$
6f: $R^{1}=R^{2}=O$

Chart 1 Structures of xylosides and xyloside analogs.

analogs with modifications in positions 2,3 , and 4 of the corresponding benzyl $\beta$-D-xylopyranosides. ${ }^{22}$ Interestingly, the authors also reported GAG priming by the 4-keto compound $\mathbf{6 f}$ (Chart 1), at similar concentrations as XylOBn (1b), and by benzyl 4- $C$-methyl- $\beta$-D-xylopyranoside (6a) at approximately 100fold higher concentrations of $\mathbf{6 a}$ compared to $\mathbf{1 b}$.

In 2013, Qasba and co-workers published the crystal structure of a substrate-enzyme complex of human $\beta 4 \mathrm{GalT} 7$, as well as that of the similar enzyme from Drosophila melanogaster. ${ }^{23,24}$ The two enzymes show a significant overlap in the catalytic pocket, and the Drosophila variety was used in co-crystallization with UDP-galactose (UDP-Gal) and xylobiose (i.e., Xylß1-4Xyl). To suppress decomposition of the UDP-Gal by the enzyme, the authors used a mutated D211N- $\beta 4$ GalT7. They proposed that the catalytic reactions are initiated by binding of UDP-Gal and a manganese ion to $\beta 4 \mathrm{GalT} 7$. This binding initiates a conformational reorganization from an open form to a closed conformation, with simultaneous formation of a xylose-binding pocket. The xylose moiety is then perfectly positioned for formation of the glycosidic bond and the authors proposed an $\mathrm{S}_{\mathrm{N}}$ 2-like mechanism, similar to the catalytic mechanism shown by $\beta 4 \mathrm{GalT1} .^{25,26}$ Furthermore, aromatic residues at the entrance of the catalytic pocket could explain the strong GAG priming shown by some xylosides with aromatic aglycons.

We hypothesize that $\beta 4$ GalT7 does not tolerate any modifications of the xylose moiety, and that it is possible to design effective inhibitors of GAG biosynthesis by modifying xylose. To pinpoint the requirements and limitations for priming and inhibition of GAG chains we synthesized, and unequivocally characterized, a collection of xyloside analogs (Chart 1). To rule out any effects due to cellular uptake of these compounds, we cloned and expressed $\beta 4 \mathrm{GalT} 7$, the enzyme that catalyzes the second step of the formation of the linker tetrasaccharide, and tested xyloside analogs in a cell-free assay.

\section{Results}

\section{Synthesis}

Benzylation of XylNap (1a) under phase transfer conditions generated a separable mixture of dibenzylated 7, 8, and 9 (Scheme 1). ${ }^{19}$ Next, the methyl group was introduced using a Dess-Martin oxidation-Grignard addition sequence, which resulted in stereoisomeric mixtures, separable by column chromatography. Finally, to avoid saturation of the naphthyl moiety, debenzylation was performed using catalytic hydrogenation in $\mathrm{HCl} / \mathrm{DMF},{ }^{27}$ which gave the expected methylated 2naphthyl $\beta$-D-xylosides 2a, 2b, 3a, 3b, 4a, and 4b. A similar procedure, using isopropylidene protection, gave the corresponding compound $\mathbf{4 g}$, carrying an ethyl group in position 4 .

Compound 5a was synthesized from per-O-acetylated L-idose $(\mathbf{1 8})^{\mathbf{2 8}}$ in a standard aromatic glycosylation, while compound $\mathbf{5 b}$ was synthesized from the commercially available 2-naphthyl $\beta$-D-glucopyranoside (5c) by a selective tosylation of position 6 followed by reduction using $\mathrm{LiAlH}_{4}$ (Scheme 2, top). Compound $\mathbf{5 d}$ is commercially available.

In addition, we intended to synthesize 6a, previously synthesized by Esko, ${ }^{22}$ due to its structural similarities with $\mathbf{4 a}$, 


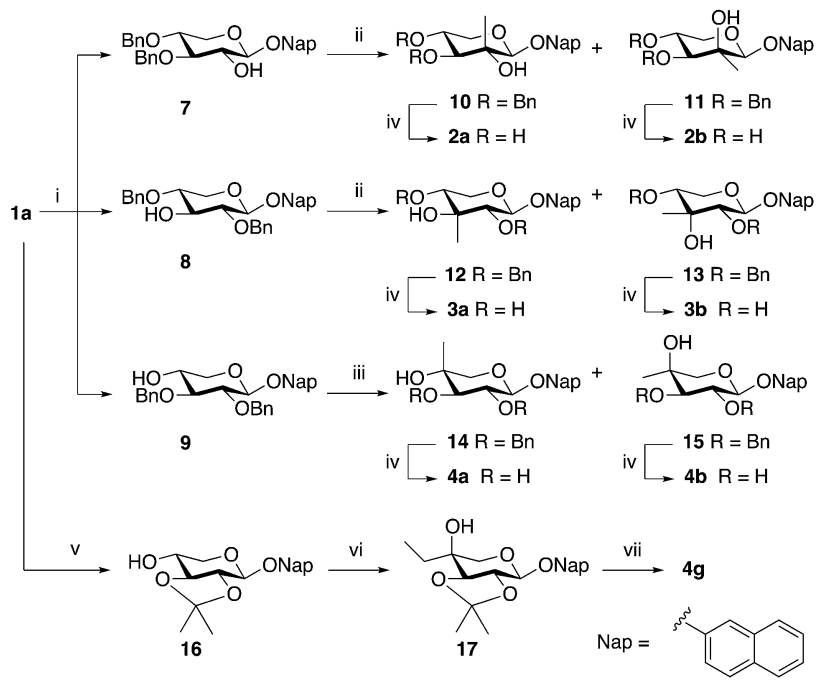

Scheme 1 Synthesis of compounds modified in positions 2, 3, and 4 . Reagents and conditions: (i) $\mathrm{BnBr}$, TBAl (cat.), $\mathrm{KOH}\left(10 \%\right.$ aq), $\mathrm{CH}_{2} \mathrm{Cl}_{2}$, r.t., 16 h, 7 (6\%), 8 (66\%), 9 (14\%); (ii) (a) 15\% Dess-Martin periodinane in $\mathrm{CH}_{2} \mathrm{Cl}_{2}, \mathrm{CH}_{2} \mathrm{Cl}_{2}$, r.t., $\mathrm{N}_{2}, 2$ h; (b) $3 \mathrm{M} \mathrm{MeMgBr}$ in $\mathrm{Et}_{2} \mathrm{O}$, r.t., $\mathrm{N}_{2}, 1.5$ h, 10 (57\%), 11 (10\%), 12 (19\%), 13 (68\%); (iii) (a) 15\% Dess-Martin periodinane in $\mathrm{CH}_{2} \mathrm{Cl}_{2}, \mathrm{CH}_{2} \mathrm{Cl}_{2}$, r.t., $\mathrm{N}_{2}, 2$ h; (b) $3 \mathrm{M} \mathrm{MeMgBr}$ in $\mathrm{Et}_{2} \mathrm{O}, 0^{\circ} \mathrm{C}$ to r.t., $\mathrm{N}_{2}$, 1.5 h, 14 (42\%), 15 (42\%); (iv) 10\% Pd/C (14\%), HCl (22 eq.), DMF, $\mathrm{H}_{2}$, r.t., 3 h, 2a $(67 \%), 2 b(44 \%), 3 a(76 \%), 3 b(49 \%), 4 a(70 \%), 4 b(54 \%) ;(v)$ 2-methoxy propene, CSA (cat.), DMF, r.t., $1.5 \mathrm{~h}$, (51\%); (vi) (a) $2 \mathrm{M}$ oxalyl chloride in $\mathrm{CH}_{2} \mathrm{Cl}_{2}, \mathrm{DMSO}, \mathrm{CH}_{2} \mathrm{Cl}_{2},-78^{\circ} \mathrm{C}, 2 \mathrm{~h}$; (b) $3 \mathrm{M} \mathrm{EtMgBr}$ in $\mathrm{Et}_{2} \mathrm{O}$, THF, r.t., 12 h, (38\%); (vii) $70 \% \mathrm{AcOH}, 1$ h, (56\%).

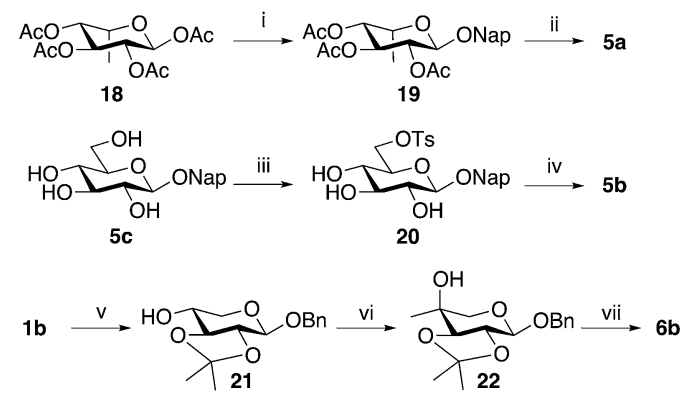

Scheme 2 Synthesis of compounds modified in position 5 and synthesis of compound $6 \mathrm{~b}$. Reagents and conditions: (i) $\mathrm{BF}_{3} \cdot \mathrm{OEt}_{2}(2.5$ eq.), $\mathrm{Et}{ }_{3} \mathrm{~N}$ (0.5 eq.), 2-naphthol (1.5 eq.), $\mathrm{CH}_{2} \mathrm{Cl}_{2}, 0{ }^{\circ} \mathrm{C}, 2 \mathrm{~h}$, (78\%); (ii) $1 \mathrm{M}$ $\mathrm{NaOMe}\left(0.1\right.$ eq.), $\mathrm{MeOH}$, r.t., 2 h, (81\%); (iii) $\mathrm{TsCl}$ (1.5 eq.), $\mathrm{ZnBr}_{2}$ (1.1 eq.), pyridine, $-25{ }^{\circ} \mathrm{C}, 1 \mathrm{~h},(86 \%)$; (iv) $\mathrm{LiAlH}_{4}\left(6 \mathrm{eq}\right.$.), THF, $30{ }^{\circ} \mathrm{C}, 22 \mathrm{~h},(61 \%)$. (v) 2-Methoxy propene (5.8 eq.), TFA (cat.), DMF, r.t., 6 h, (47\%); (vi) (a) 2 $\mathrm{M}$ oxalyl chloride in $\mathrm{CH}_{2} \mathrm{Cl}_{2}$ (3 eq.), DMSO (6 eq.), $\mathrm{CH}_{2} \mathrm{Cl}_{2},-78^{\circ} \mathrm{C}, 2 \mathrm{~h}$ (b) $3 \mathrm{M} \mathrm{MeMgBr}$ in $\mathrm{Et}_{2} \mathrm{O}$ (3 eq.), THF, r.t., 12 h, (55\%); (vii) Dowex 50Wx4, $\mathrm{MeOH}$, r.t., 4 h, (56\%).

following the original procedure (Scheme 2, bottom). Starting from benzyl $\beta$-D-xylopyranoside $(\mathbf{1 b}),{ }^{29}$ selective protection of 2$\mathrm{OH}$ and 3-OH, using 2-methoxy propene and CSA in DMF, gave 21 in $47 \%$ yield with an additional $12 \%$ of the corresponding 3,4-protected analog. Next, the methyl group was introduced in 21, using a Swern oxidation-Grignard addition sequence. To our surprise, compound 22 was the only isolated product. Finally, deprotection of 22 with acidic ion exchange resin in methanol, gave benzyl 4-methyl- $\beta$-D-arabinopyranoside $(\mathbf{6 b})$ in
$56 \%$ yield. Conformational analysis, vide infra, unequivocally confirmed an equatorial orientation of the 4-C-methyl group. It is reasonable to believe that the structure of the compound synthesized and tested by Esko and co-workers was $\mathbf{6 b}$ rather than $6 a$.

\section{Configurational and conformational analysis}

The stereochemical assignments of the endocyclic tertiary carbon atoms are based on ${ }^{1} \mathrm{H},{ }^{1} \mathrm{H}$ nuclear Overhauser effects (NOEs), ${ }^{3} J_{\mathrm{C}, \mathrm{H}}$ and ${ }^{3} J_{\mathrm{H}, \mathrm{H}}$ coupling constants, ${ }^{13} \mathrm{C}$ and ${ }^{1} \mathrm{H}$ chemical shifts. With these at hand, the extent of the major conformation of each compound was assessed. The ${ }^{1} \mathrm{H}$ and ${ }^{13} \mathrm{C}$ chemical shifts of the xylose residues were assigned by $1 \mathrm{D}^{1} \mathrm{H}$ and ${ }^{13} \mathrm{C}$ experiments in conjunction with a few $2 \mathrm{D}{ }^{1} \mathrm{H},{ }^{1} \mathrm{H}$ - and ${ }^{1} \mathrm{H},{ }^{13} \mathrm{C}$-correlated experiments (ESI†).

Axially oriented methyl groups are in close proximity to axial hydrogen atoms on $\gamma$-carbons as well as vicinal hydrogen atoms, whereas equatorial methyl groups are proximate only to vicinal hydrogen atoms (in the ${ }^{4} C_{1}$ conformation). Employing $1 \mathrm{D}{ }^{1} \mathrm{H},{ }^{1} \mathrm{H}$-DPFGSE-NOESY experiments, ${ }^{30}$ selective excitation of the methyl groups in compounds $2 \mathbf{a}, \mathbf{2 b}, \mathbf{3 a}, \mathbf{3 b}, \mathbf{4 a}$, and $\mathbf{4 b}$ resulted in the NMR spectra displayed in Fig. 2. The 2-(R)configuration (i.e., axial orientation of methyl group) of compound 2a was assigned via a prominent NOE-correlation from the methyl protons to H4 (Fig. 2). For compound $2 \mathbf{b}$, NOEcorrelations were only observed to $\mathrm{H} 1$ and $\mathrm{H} 3$, which supports an equatorially oriented methyl group and hence a $2-(S)$ configuration. The 3-(S)-configuration of compound $\mathbf{3 a}$ was assigned via NOE-correlations from the methyl protons to H1 and H5pro-S, whereas these were essentially absent in compound $\mathbf{3 b}$. The stereochemical assignment at $\mathrm{C} 4$ of compound 4a was partly obstructed due to overlap of the $\mathrm{H} 2$ and $\mathrm{H} 3$ resonances in the ${ }^{1} \mathrm{H}$ NMR spectrum. However, a stronger correlation between the methyl group and H5pro- $R$ than between the methyl group and H5pro-S was observed, which indicates an axial orientation and consequently the $4-(R)$ -

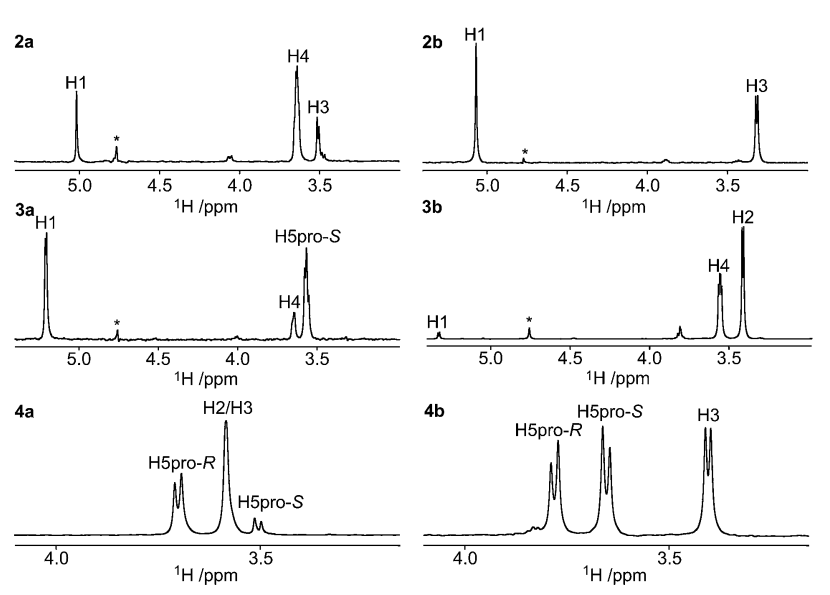

Fig. 2 Selected regions of $1 \mathrm{D}{ }^{1} \mathrm{H},{ }^{1} \mathrm{H}$-NOESY spectra of compounds $2 a-b, 3 a-b$, and $4 a-b$ (top to bottom) in methanol- $d_{4}$ as solvent. Selective excitation was carried out on the proton resonance from the $C$-methyl group using a $\tau_{\text {mix }}$ of $0.41 \mathrm{~s}$ in the experiment. An asterisk marks residual $\mathrm{CD}_{3} \mathrm{OH}$ solvent peak. 
configuration. For compound $\mathbf{4} \mathbf{b}$, NOEs of similar magnitudes were observed for the signals of $\mathrm{H} 3, \mathrm{H} 5$ pro- $R$, and H5pro- $S$, when irradiating the methyl resonance, which clearly indicates an equatorial orientation of the methyl group and thus the 4- $(S)$ configuration. Selective excitation of the methyl group in compound $\mathbf{6 b}$ gave a nearly identical NOE result to that observed for compound $\mathbf{4} \mathbf{b}$.

According to Karplus-type equations, ${ }^{31-33}$ the ${ }^{3} J_{\mathrm{CH}}$ coupling constants from the ${ }^{13} \mathrm{C}$ nuclei of axially oriented methyl groups to axial vicinal protons should be larger compared to those from equatorially oriented methyl groups. Selected ${ }^{3} J_{\mathrm{CH}}$ coupling constants were measured via the 1DLR experiment, ${ }^{34,35}$ that relies on selective excitation of ${ }^{13} \mathrm{C}$ resonances followed by evolution of the heteronuclear coupling and detection on the ${ }^{1} \mathrm{H}$ nuclei. Heteronuclear coupling constants were determined by modified $J$ doubling in the frequency domain. ${ }^{36}$ In all cases of the pairwise comparisons for the diastereomeric pairs, $2 \mathbf{a}$ and $\mathbf{2 b}, \mathbf{3 a}$ and $\mathbf{3 b}$, as well as $\mathbf{4 a}$ and $\mathbf{4 b}$, we observed larger ${ }^{3} J_{\mathrm{CH}}$ coupling constants for $\mathbf{2 a}, \mathbf{3} \mathbf{a}$, and $\mathbf{4 a}$, compared to $\mathbf{2} \mathbf{b}, \mathbf{3} \mathbf{b}$, and 4b. This is consistent with an antiperiplanar arrangement in the former set of molecules. The observed ${ }^{3} J_{\mathrm{CH}}$ coupling constants for compound $\mathbf{6 b}$ were similar to those observed for compound $\mathbf{4 b}$, verifying the 4 - $(S)$-configuration of $\mathbf{6} \mathbf{b}^{22}$

In all diastereomeric pairs, the ${ }^{13} \mathrm{C}$ chemical shifts of axial methyl groups were shifted upfield compared to those of equatorial methyl groups, ${ }^{37}$ with inter-pair differences ranging from 2-6 ppm. The ${ }^{1} \mathrm{H}$ chemical shifts of axial protons in $\gamma$-position to the methyl groups were shifted downfield when the methyl groups were oriented equatorially, hydroxyl groups thus being axial, in compounds $2 \mathbf{b}, \mathbf{3 b}$, and $\mathbf{4 b}$. This is in accordance with what is seen for $\delta_{\mathrm{H} 5}$ of hexapyranosides with respect to a change in anomeric configuration. ${ }^{38}$ Typically, a downfield chemical shift displacement $\Delta \delta_{\mathrm{H}}$ of $0.2 \mathrm{ppm}$ was observed upon a 1,3-syn-axial interaction with an oxygen atom.

Deviations from the ${ }^{4} C_{1}$ conformation can be observed and quantified to some extent by ${ }^{3} J_{\mathrm{HH}}$ coupling constant analysis. The compounds bearing axial methyl groups, 2a, 3a, and $\mathbf{4 a}$, have smaller ${ }^{3} J_{\mathrm{HH}}$ coupling constants than their respective diastereoisomers. The maximum values of ${ }^{3} J_{\mathrm{H} 1, \mathrm{H} 2},{ }^{3} \mathrm{~J}_{\mathrm{H} 2, \mathrm{H} 3}$, ${ }^{3} J_{\mathrm{H} 3, \mathrm{H} 4}$, and ${ }^{3} J_{\mathrm{H} 4, \mathrm{H} 5 \text { pro- } S}$, correspond to the ${ }^{4} C_{1}$ conformation; thus, the observed coupling differences arise due to population contributions of non- ${ }^{4} C_{1}$ conformers for these compounds. This is in agreement with the expected larger 1,3-diaxial steric repulsion of a methyl group compared to a hydroxyl group. The larger coupling constant deviations observed for compound 3a, compared to all other compounds reflect, with respect to steric repulsion, the significance of the number of 1,3-diaxial hydrogen atoms in relation to the axial methyl substituent, two for $\mathbf{3 a}$ and one for $\mathbf{2 a}$ and $\mathbf{4 a}$.

Plausibly populated non- ${ }^{4} C_{1}$ conformers are the skew conformers ${ }^{1} S_{5}$ and ${ }^{2} S_{\mathrm{O}}$, and the ${ }^{1} C_{4}$ conformation. The ${ }^{2} S_{\mathrm{O}}$ conformation has previously been shown to be present in xylose derivatives. ${ }^{19}$ In compound $\mathbf{4 a}$, the methyl group would be oriented pseudo-equatorially in the ${ }^{2} S_{\mathrm{O}}$ conformation. In compound 2a, however, the ${ }^{2} S_{\mathrm{O}}$ conformation would increase steric interactions between the methyl group and H5pro- $R$. Rather, the ${ }^{1} S_{5}$ conformation seems beneficial for compound 2a, by placing the methyl group in pseudo-equatorial orientation and the anomeric substituent in pseudo-axial orientation. For compound 3a, the ${ }^{1} S_{5}$ and/or ${ }^{2} S_{\mathrm{O}}$ conformations would be feasible non- ${ }^{4} C_{1}$ states. The ${ }^{1} C_{4}$ conformation would relieve steric strain in compounds $\mathbf{2 a}, \mathbf{3 a}$, and $\mathbf{4 a}$ by orienting the respective methyl groups equatorially, and benefit from the anomeric effect by placing the exo-anomeric oxygen in an axial orientation. Estimates based on the available ${ }^{3} J_{\mathrm{HH}}$ data suggest that up to about $20 \%$ of the conformational space for compounds $2 \mathbf{a}$ and $3 \mathbf{a}$ are occupied by non $-{ }^{4} C_{1}$ conformations, whereas up to $10 \%$ is the suggested figure for compound $\mathbf{4 a}$ and $<10 \%$ for compounds $\mathbf{2 b}, \mathbf{3 b}, \mathbf{4 b}$, and $\mathbf{6 b}$.

Employing the above described methodology to additional xyloside compounds resulted in $>90 \%$ of the ${ }^{4} C_{1}$ conformation for $\mathbf{4 f}$, solely the ${ }^{4} C_{1}$ conformation for $\mathbf{4 g}$, an equilibrium between the ${ }^{4} C_{1},{ }^{2} S_{\mathrm{O}}$, and ${ }^{1} C_{4}$ conformations being $\sim 1 / 4, \sim 1 / 4$, and $\sim 1 / 2$, respectively, for $\mathbf{5 a}$ where the ${ }^{2} S_{\mathrm{O}}$ conformation is supported by a conspicuous NOE between the $\mathrm{H} 5$ and $\mathrm{H} 2$ protons, ${ }^{39}$ and solely the ${ }^{4} C_{1}$ conformation for $\mathbf{5 b}$.

To summarize, we have unequivocally determined the configurations of each stereocenter in the synthesized target compounds described above (Schemes 1 and 2). Furthermore, we observed that the majority of our xyloside analogs preferentially adopts the ${ }^{4} C_{1}$ conformation. Compounds bearing axial methyl groups are exceptions, and for compound $5 \mathbf{a}$, the ${ }^{1} C_{4}$ conformation seems to be most populated.

\section{$\beta 4 G a l T 7$ assay}

A truncated version of $\beta 4 \mathrm{GalT7}$ fused with glutathione $S$-transferase (GST) was expressed in E. coli, yielding $12 \mathrm{mg}$ of purified ( $>95 \%$ by SDS PAGE) protein per liter of growth medium. As previously reported, ${ }^{\mathbf{4 0}}$ the truncated $E$. coli expression product of $\beta 4$ GalT7 fused to GST does not substantially affect substrate binding and catalytic properties of $\beta 4 \mathrm{GalT7}$, compared to the membrane-bound mammalian product. This enabled us to use the bacterial product as a model for the mammalian enzyme.

XylNap (1a) is known to be a primer of GAG chains, and is thereby a substrate for $\beta 4 \mathrm{GalT7}$ (Fig. 1b). The activity of $\beta 4 \mathrm{GalT7}$ was thus determined using XylNap as acceptor substrate and UDP-Gal as donor substrate. The reaction time and the amount of enzyme were chosen so that the production of disaccharide, that is GalXylNap, showed first-order dependence of these two parameters. The reaction progress was analyzed by HPLC using fluorescence detection. We thus observed a new peak with a shorter retention time than XylNap and with a mass spectra corresponding to GalXylNap (Fig. 3a). The recombinant $\beta 4$ GalT7 showed Michaelis-Menten kinetics for XylNap with a $K_{\mathrm{M}}$ value of $0.78 \mathrm{mM}$ (Fig. 3b). In accordance with the literature, ${ }^{\mathbf{4 1}}$ the enzyme showed excess-substrate inhibition from UDP-Gal, and the $K_{\mathrm{M}}$ value for UDP-Gal $(0.35 \mathrm{mM})$ was comparable to previously reported data. ${ }^{\mathbf{4 0}-42}$ The solubilities of the xylosides in DMSO limited the maximum concentration of substrate that could be added in the assay to approximately $2.5 \mathrm{mM}$.

To determine if our synthesized xyloside analogs could serve as substrates for $\beta 4 \mathrm{GalT7}$ (i.e., if the analogs are galactosylated), each compound was added as the only acceptor substrate in the 


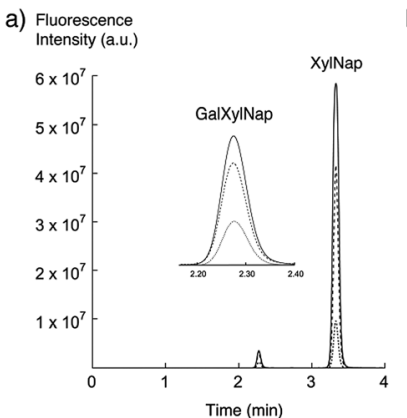

b)
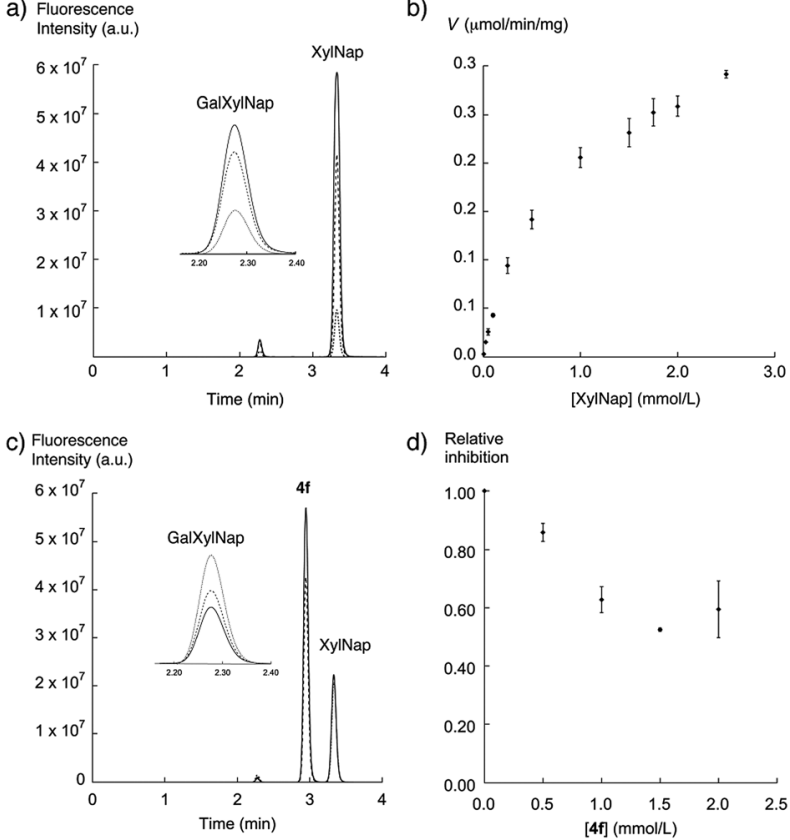

d) Relative

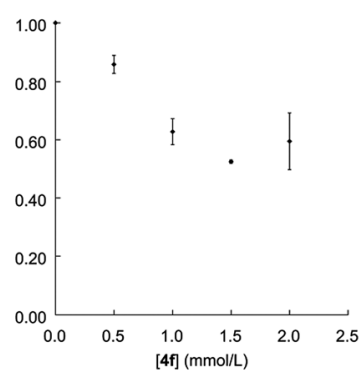

Fig. 3 Galactosylation and inhibition of galactosylation by $\beta 4$ GalT7. (a) HPLC chromatograms for galactosylation experiments with XyINap. The GalXylNap peak is increasing with increasing concentrations of XylNap; $0.25 \mathrm{mM}$ (dotted line), $1.0 \mathrm{mM}$ (dashed line), and $2.0 \mathrm{mM}$ (solid line). (b) Michelis-Menten representation of the activity of $\beta 4 \mathrm{GalT7}(\mathrm{V})$ as a function of the XylNap concentration. (c) HPLC chromatograms for inhibition experiments with $\mathbf{4 f}$. The GalXylNap peak is decreasing with increasing concentrations of $4 \mathrm{f} ; 0 \mathrm{mM}$ (dotted line), $0.5 \mathrm{mM}$ (dashed line), and $1.5 \mathrm{mM}$ (solid line). (d) Relative inhibition of GalXylNap plotted versus the concentration of $4 \mathrm{f}$. The areas of the GalXylNap peaks, upon addition of $\mathbf{4 f}$, are compared to the areas of the GalXyINap peaks without inhibitor.

$\beta 4$ GalT7 assay (Fig. 3c and d). As expected, most of these xyloside analogs failed to act as substrates for $\beta 4 \mathrm{GalT7}$, with exceptions for compounds $\mathbf{2 a}, \mathbf{2 d}, \mathbf{2 e}$, and $\mathbf{5 a}$ that showed weak galactosylation, compared to XylNap (Fig. 4, white bars). In each case of galactosylation, the mass spectra for the corresponding galactosylated products were determined, and were in all cases found to be accurate.

Previous studies have shown GAG inhibitory effects of specific xyloside analogs. ${ }^{19-21}$ To determine the inhibitory activity of our compounds, XylNap was used as mimic of the natural substrate (i.e., the xylosylated PG core protein). A fixed amount of XylNap was added, together with different concentrations of the xyloside analogs, and the amount of formed GalXylNap was measured. A decrease in GalXylNap formation, compared to the control, indicates that the compound is an inhibitor of the enzyme (Fig. $3 \mathrm{c}$ and $\mathrm{d}$ ). Interestingly, we observed a weak decrease in GalXylNap formation in the presence of compounds $2 \mathbf{c}, \mathbf{2 d}, \mathbf{3 d}, \mathbf{4 e}$, and $\mathbf{4 g}$, and significant reduction of GalXylNap formation for compounds $2 \mathbf{e}, \mathbf{4 b}, \mathbf{4 d}$, and 4 f. The results are shown in Fig. 4 (black bars) and discussed below (detailed data in ESI $\dagger$ ). To conclude, any modification of the xylose moiety rendered analogs unable to function as efficient substrates for $\beta 4 \mathrm{GalT7}$, and several compounds showed effective inhibition of $\beta 4 \mathrm{GalT7}$.

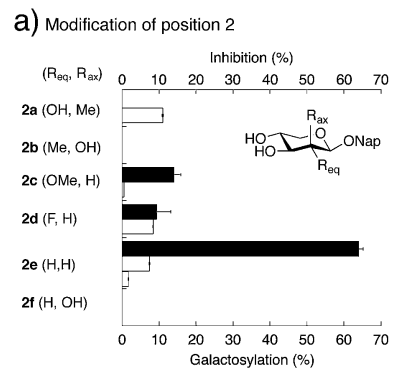

b) Modification of position 3

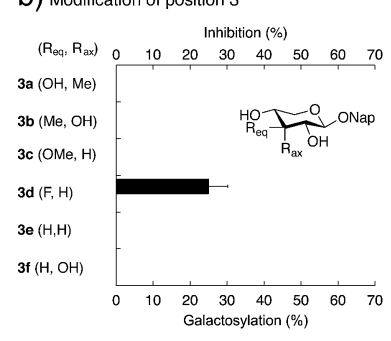

C) Modification of position 4

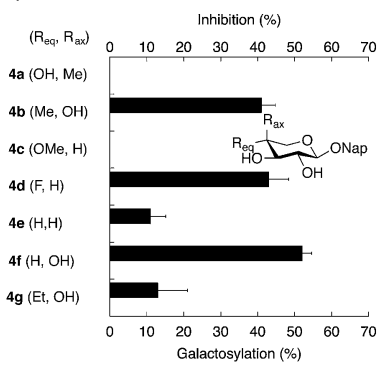

d) Modification of position 5

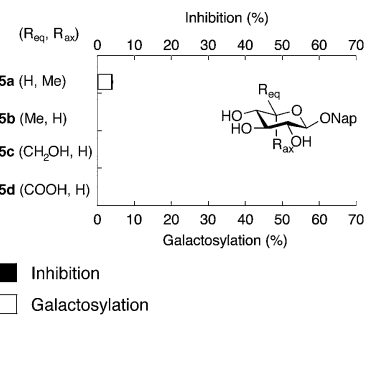

Fig. 4 Galactosylation and inhibition of galactosylation by $\beta 4$ GalT7. White bars indicate amount of galactosylation (\% of the effect shown by XylNap). Black filled bars show inhibition of galactosylation of XylNap (\% of control without added xyloside analog; $0.5 \mathrm{mM}$ of XylNap and $2.0 \mathrm{mM}$ of xyloside analog). The $y$-axis displays compound number in bold face (the substituent in equatorial orientation, axial orientation). Compound $2 \mathrm{e}$ is displayed by two white bars. This compound is probably galactosylated at two different positions.

\section{Effects on GAG priming in cells}

As previously mentioned, the GAG priming abilities of XylNap (1a), as well as of compounds $\mathbf{2 c - f}, \mathbf{3 c - f}$, and $\mathbf{4 c - f}$ have been investigated earlier in HCC70 cells and CCD-1095Sk cells. ${ }^{19}$ Here, we investigated the GAG priming abilities of XylNap and compounds 2a, 2b, 3a, 3b, 4a, 4b, 4g, 5a, 5b, and 6b using XT deficient pgsA-745 cells. Since these cells are incapable of synthesizing complete PGs, they produce very small amounts of endogenous GAG chains. This make them suitable for investigations of xyloside priming. The cells were incubated with the xyloside analogs in low sulfate medium supplemented with $\left[{ }^{35} \mathrm{~S}\right]$ sulfate. After $5 \mathrm{~h}$ of incubation, the GAG chains were isolated from the culture media and the amount of radioactivity in each sample was counted. Except for XylNap, no xyloside analog induced significant priming of GAG chains (data not shown).

To investigate if the inhibitory effects observed in the $\beta 4$ GalT7 assay were transferable to cell culture studies, HCC70 cells were treated with either XylNap alone or with equimolar amounts $(0.1 \mathrm{mM})$ of compounds $4 \mathbf{b}$ or $4 \mathbf{d}$. After $24 \mathrm{~h}$ of incubation in low-sulfate medium, supplemented with $\left[{ }^{35} \mathrm{~S}\right]$ sulfate and xyloside analogs, the GAG chains were isolated from the culture media. The samples were run on a Superose 6 column and the radioactivity was measured (Fig. 5). The addition of either $\mathbf{4 b}$ or $\mathbf{4 d}$ resulted in a decrease of GAG chains primed from XylNap, corresponding to $50 \%$ and $25 \%$, respectively. To conclude, this indicates that the results from the enzymatic investigations of $\beta 4 \mathrm{GalT7}$ (that is galactosylation and its inhibition) also can be observed in cellular systems. 


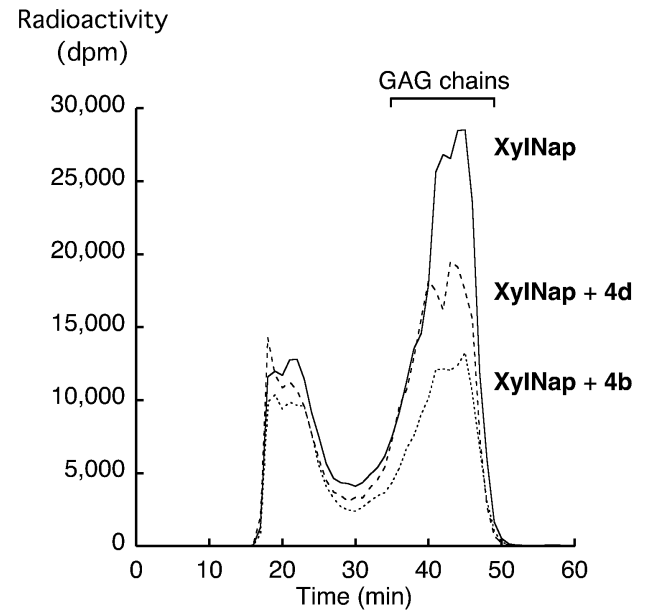

Fig. 5 Superose 6 -profiles for $\left[{ }^{35} \mathrm{~S}\right]$ sulfate-labeled material isolated from HCC70 cells after treatment with XylNap (solid line), XylNap and 4d (dashed line), and XylNap and $4 \mathrm{~b}$ (dotted line).

\section{Discussion}

By combining our structure-activity relationship studies with the known crystal structure of $\beta 4 \mathrm{GalT7}$, we can now provide a detailed model for binding of xylosides and xyloside analogs to $\beta 4 \mathrm{GalT7}$.

Most modifications of position 2 in xylose, rendered analogs less prone to galactosylation, compared to XylNap (1a). However, we observed weak galactosylation of compound 2a, carrying an axial methyl group, in contrast to $\mathbf{2 b}$. The 2 -fluoro analog 2d showed galactosylation and inhibition, whereas the 2methoxy analog 2c showed inhibition similar to $\mathbf{2 d}$ and very weak galactosylation. This indicates that the hydroxyl group in position 2 might acts as a hydrogen bond acceptor. Interestingly, the 2-deoxy analog $2 \mathrm{e}$ showed formation of two different compounds. Compound 2e lacks substituents in both $\mathrm{C} 2$ and C5 of the xylose moiety, and thus shows pseudo-rotational symmetry. It is reasonable that it fits the active site in the enzyme in two different orientations and can be galactosylated at both position 3 and 4 . Compound 2e, also showed very efficient inhibition of galactosylation (64\%), possibly explained by the flexibility in binding orientation.

Modifications of position 3 resulted in inactive compounds, with the exception of the 3-deoxy-3-fluoro analog $\mathbf{3 d}$. The fluoro substituent is similar in size as a hydroxyl group and can probably accept a hydrogen bond from Asp211, but with a reversed hydrogen bond pattern (Fig. 6). From inspection of the crystal structure, ${ }^{23}$ it is obvious that the binding pocket is narrow and compound 3c, carrying a sterically more demanding methoxy group, does not fit, and is thus inactive. The importance of the $3-\mathrm{OH}$ is further validated by the deoxy compound 3e, which showed no galactosylation or inhibition.

From the perspective of inhibitor design, our results indicate that position 4 is the most interesting. The addition of an axial methyl group, compound $\mathbf{4 a}$, rendered an inactive compound while the epimeric analog $\mathbf{4 b}$, carrying an equatorial methyl group and an axial hydroxyl group, showed strong inhibition. In

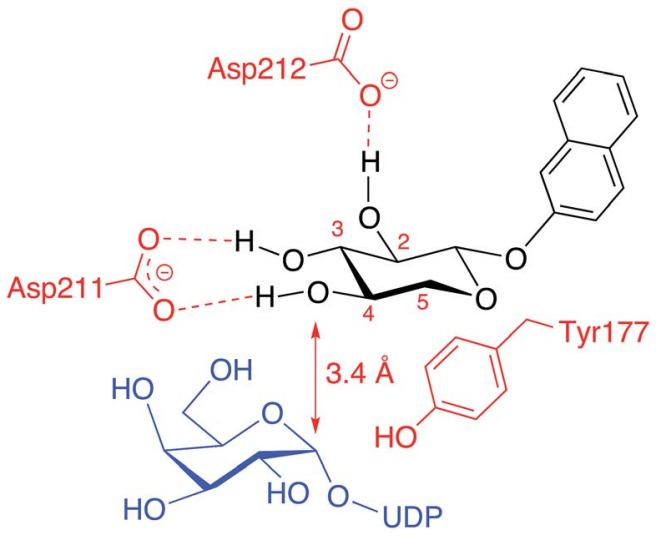

Fig. 6 Proposed binding pattern of xylosides and UDP-Gal in the binding pocket of $\beta 4 \mathrm{GalT7}$.

order to understand these results, we performed molecular modeling based on X-ray diffraction data of the Drosophila B4GalT7 mutant D211N (PDB ID 4M4K), using Schrödinger 2013 software suite, with the OPLS-2005 force field and GB/SA solvation for water. The xylose moiety of XylNap adopts a very similar orientation and binding mode as the xylobiose in the crystal structure (Fig. 7a).

From our conformational analysis vide supra, we conclude that compound $\mathbf{4 b}$ is locked to a ${ }^{4} C_{1}$ conformation. Interestingly, in this conformation, the axial $4-\mathrm{OH}$ group is positioned in an orientation suitable for nucleophilic attack with ample space for the equatorial methyl group (Fig. 7b). However, in the axial orientation it is not possible to form the important hydrogen bond from 4-OH to Asp211, which results in diminished nucleophilicity of $\mathrm{O} 4$ of xylose moiety (Fig. 6). Consequently, this compound acts as an inhibitor of galactosylation rather than a substrate for galactosylation. On the contrary, the axial methyl group in compound $\mathbf{4 a}$ clearly eliminates the possibility for nucleophilic substitution due to steric hindrance, and this compound showed no galactosylation or inhibition (Fig. 7c).

As previously mentioned, Esko and co-workers reported a study of substituted benzyl xylosides and the amount of GAG priming on these compounds in pgsA-745 cells. ${ }^{22}$ As expected, most modifications of the 4-hydroxyl group, such as methylation, deoxygenation, or epimerization (Chart 1, compounds $6 \mathbf{c}-$ e), rendered inactive compounds. On the contrary, methylation of positions 2 or 3 gave analogs that initiated GAG priming, although at higher concentrations compared to XylOBn (1) The 3-deoxy-3-fluoro analog induced priming at approximately 10-fold higher concentrations compared to the parent compound. Interestingly, the authors reported priming of GAG chains by benzyl 4- $C$-methyl- $\beta$-D-xylopyranoside (6a) at approximately 100-fold higher concentrations compared to XylOBn. Our attempts to synthesize compound 6a, using the same method as Esko and co-workers, resulted in the epimeric $\mathbf{6 b}$, a compound very difficult to distinguish from 6a. As mentioned, when investigating the structurally similar compounds $\mathbf{4 a}$ and 4b, no significant galactosylation could be observed. Instead, compounds $\mathbf{4 b}$ and $\mathbf{6 b}$ acted as inhibitors of $\beta 4 \mathrm{GalT} 7$ and compound $\mathbf{6 b}$ showed $43 \%$ inhibition (ESI†). 


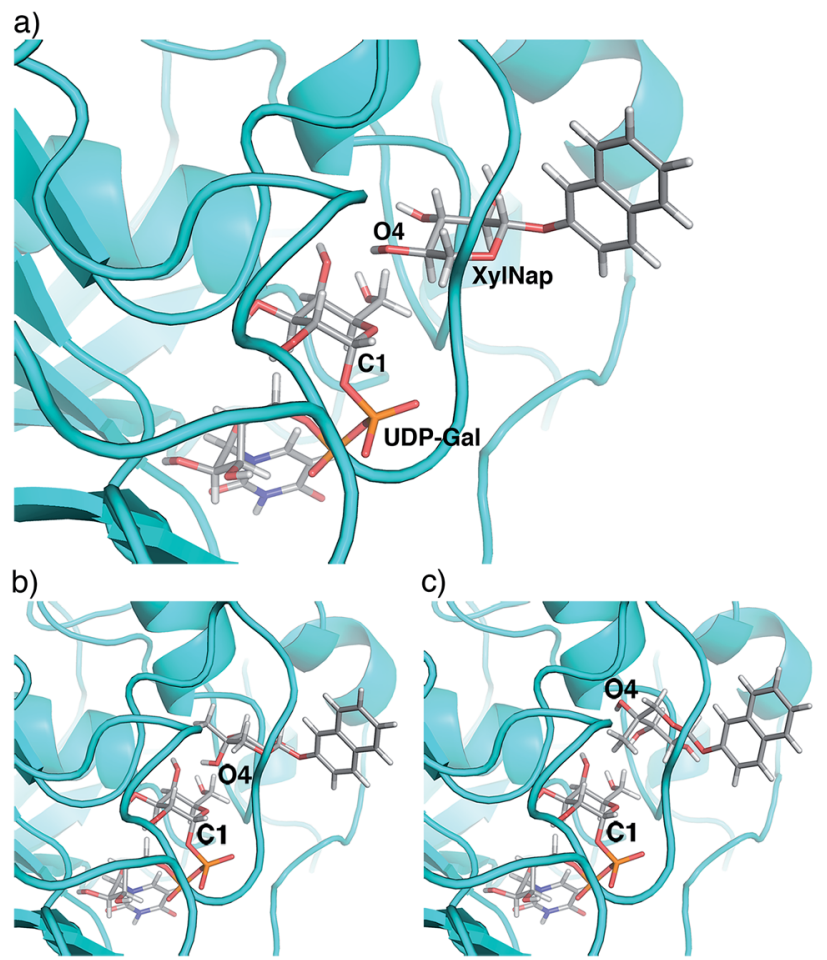

Fig. 7 Molecular modeling of xylosides in $\beta 4$ GalT7. (a) $\bigcirc 4$ of the xylose moiety in XyINap (1a) is oriented for nucleophilic substitution on C1 of UDP-Gal. The xylose moiety adopts a very similar orientation and binding mode as the original xylobiose in the crystal structure. (b) In compound $4 \mathrm{~b}$, the axial $4-\mathrm{OH}$ is situated in an orientation suitable for nucleophilic substitution, similar to XylNap. However, the loss of one hydrogen bond results in diminished nucleophilicity. (c) In $4 a$, the possibility for nucleophilic substitution is eliminated due to steric hindrance from the axial methyl group.

It is worth to notice that the galactosylation of XylNap is very efficient and in our hands, using pgsA-745 cells, we observed maximum GAG priming on XylNap at concentrations of 0.1 $\mathrm{mM}$. In our initial studies, we did observe significant priming for compounds $\mathbf{2 b}, \mathbf{4 b}$, and $\mathbf{6 b}$ at $1 \mathrm{mM}$ in pgsA-745 cells, very similar to the results of Esko and co-workers. However, upon close inspection using fluorescence detection, we realized that these samples were contaminated with trace amounts of XylNap. This was enough to give false dose response curves in our studies. After careful HPLC purification, we observed no significant GAG priming from these compounds (see ESI $\dagger$ for an elaborate discussion).

The absence of an equatorial methyl group, as in compound 4f, resulted in an even stronger inhibition (52\%) whereas the addition of a sterically demanding ethyl group resulted in a diminished inhibitory effect $(\mathbf{4 g}, 13 \%)$, compared to $4 \mathbf{b}(41 \%)$. We propose that xyloside analogs with axial hydroxyl groups in position 4 can act as strong inhibitors of galactosylation and that the corresponding equatorial groups induce steric hindrance and diminished inhibition.

As expected, in the absence of a hydroxyl group, the deoxy compound 4e and the 4-fluoro analog 4d did not show any galactosylation. However, 4d showed strong inhibition of galactosylation. These results were transferable to cell studies and we observed $50 \%$ inhibition of XylNap induced GAG synthesis in HCC70 cells by compound $\mathbf{4 b}$ and $25 \%$ by compound $\mathbf{4 d}$. As previously mentioned, Kuberan and co-workers reported a 4-fluoro analog with up to $90 \%$ inhibition in CHO cells. ${ }^{\mathbf{2 0 2 1}}$

The methyl analog 5a showed very weak galactosylation and no inhibition. Interestingly, this analog adopts the unusual ${ }^{2} S_{\mathrm{O}}$ conformation. It is reasonable to assume that the addition of an axial methyl group results in a compound that is tolerated by the enzyme, due to a conformational change, but that this analog is a less preferred substrate for $\beta 4 \mathrm{GalT} 7$. Any equatorial groups in position 5 , compounds $\mathbf{5 b}$-d gave complete loss of activity. These analogs are conformationally rigid and locked to the ${ }^{4} C_{1}$ conformation, in which the group in position 5 induces strong steric hindrance. From the crystal structure, it is apparent that both $\mathrm{O} 3$ and $\mathrm{O} 4$ of the xylose moiety form hydrogen bonds to the side chain of Asp211, whereas the hydrophobic moiety of Tyr177 interacts with C5 of xylose, and thus determines the specificity. Consequently, it was shown that a mutation of Tyr177 to Gly changes the specificity from xylose to glucose..$^{23,24}$

\section{Conclusions}

We have synthesized a number of xyloside analogs for exploration of the $\beta 4 \mathrm{GalT} 7$ active site. The identity and conformation of these compounds have been determined by several NMR techniques in combination with molecular modeling. The abilities of these compounds to act as substrates or inhibitors of $\beta 4 \mathrm{GalT7}$ have been investigated in a cell-free assay and further validated by cell studies.

We conclude that the binding pocket of $\beta 4 \mathrm{GalT} 7$ is very narrow and decorated with a precise set of hydrogen bond acceptors. From our data, we propose that xylose is the optimal substrate for galactosylation. Every single hydrogen bond is necessary for efficient galactosylation of xylosides, and any modification renders less active or inactive compounds. Consequently, we anticipate that it is difficult to synthesize better substrates by modification of the xylose moiety. However, modifications of the aglycon could provide more efficient substrates.

In contrast to the limited options for design of GAG primers, we open up for development of very tight binders that can function as inhibitors of galactosylation, and presumably, depending on cell permeability, act as strong inhibitors of the GAG biosynthesis. Such compounds would be valuable tools for the exploration of GAG and PG biosynthesis in normal cells and tumor cells, and we speculate in that such inhibitors may be a starting point for development of pharmaceuticals. The main target for modifications of the xylose moiety is position 4 , where a number of structural analogs show strong inhibition. Of special interest is epimerization of the $4-\mathrm{OH}$ group, which results in potent inhibitors and consequently absence of galactosylation.

\section{Acknowledgements}

This work was supported by grants from the Alfred Österlund Foundation, the Crafoord Foundation, the Evy and Gunnar 
Sandberg Foundation, Greta and John Kock, the Gunnar Nilsson Cancer Foundation, the Heart \& Lung Foundation, the Knut and Alice Wallenberg Foundation, the Koch Foundation, Lars Hiertas Memorial Foundation, the Magnus Bergwall Foundation, the Medical Faculty of Lund University, Lund University, the Royal Physiographic Society in Lund, Syskonen Svenssons Foundation for Medical Research, the Swedish Cancer Society, the Swedish Medical Research Council (11550), and the Swedish Research Council.

\section{Notes and references}

1 G. W. Yip, M. Smollich and M. Gotte, Mol. Cancer Ther., 2006, 5, 2139.

2 M. M. Fuster and J. D. Esko, Nat. Rev. Cancer, 2005, 5, 526.

3 R. Sasisekharan, Z. Shriver, G. Venkataraman and U. Narayanasami, Nat. Rev. Cancer, 2002, 2, 521.

4 D. Liu, Z. Shriver, G. Venkataraman, Y. El Shabrawi and R. Sasisekharan, Proc. Natl. Acad. Sci. U. S. A., 2002, 99, 568. 5 C. Götting, J. Kuhn, R. Zahn, T. Brinkmann and K. Kleesiek, J. Mol. Biol., 2000, 304, 517.

6 R. Almeida, S. B. Levery, U. Mandel, H. Kresse, T. Schwientek, E. P. Bennett and H. Clausen, J. Biol. Chem., 1999, 274, 26165.

7 H. C. Robinson, M. J. Brett, P. J. Tralaggan, D. A. Lowther and M. Okayama, Biochem. J., 1975, 148, 25.

8 N. B. Schwartz, L. Galligani, P. L. Ho and A. Dorfman, Proc. Natl. Acad. Sci. U. S. A., 1974, 71, 4047.

9 M. Jacobsson, U. Ellervik, M. Belting and K. Mani, J. Med. Chem., 2006, 49, 1932.

10 C. O. Abrahamsson, U. Ellervik, J. Eriksson-Bajtner, M. Jacobsson and K. Mani, Carbohydr. Res., 2008, 343, 1473.

11 T. A. Fritz, F. N. Lugemwa, A. K. Sarkar and J. D. Esko, J. Biol. Chem., 1994, 269, 300.

12 M. Jacobsson, K. Mani and U. Ellervik, Bioorg. Med. Chem., 2007, 15, 5283.

13 M. Jacobsson, C. Winander, K. Mani and U. Ellervik, Bioorg. Med. Chem. Lett., 2008, 18, 2451.

14 R. Johnsson, K. Mani and U. Ellervik, Bioorg. Med. Chem., 2007, 15, 2868.

15 R. Johnsson, K. Mani and U. Ellervik, Bioorg. Med. Chem. Lett., 2007, 17, 2338.

16 S. O. Kolset, K. Sakurai, I. Ivhed, A. Overvatn and S. Suzuki, Biochem. J., 1990, 265, 637.

17 F. N. Lugemwa and J. D. Esko, J. Biol. Chem., 1991, 266, 6674.

18 X. V. Victor, T. K. Nguyen, M. Ethirajan, V. M. Tran, K. V. Nguyen and B. Kuberan, J. Biol. Chem., 2009, 284, 25842 .

19 A. Siegbahn, U. Aili, A. Ochocinska, M. Olofsson, J. Rönnols, K. Mani, G. Widmalm and U. Ellervik, Bioorg. Med. Chem., 2011, 19, 4114.
20 D. R. Garud, V. M. Tran, X. V. Victor, M. Koketsu and B. Kuberan, J. Biol. Chem., 2008, 283, 28881.

21 Y. Tsuzuki, T. K. Nguyen, D. R. Garud, B. Kuberan and M. Koketsu, Bioorg. Med. Chem. Lett., 2010, 20, 7269.

22 F. N. Lugemwa, A. K. Sarkar and J. D. Esko, J. Biol. Chem., 1996, 271, 19159.

23 Y. Tsutsui, B. Ramakrishnan and P. K. Qasba, J. Biol. Chem., 2013, 288, 31963.

24 B. Ramakrishnan and P. K. Qasba, J. Biol. Chem., 2010, 285, 15619.

25 M. Krupicka and I. Tvaroska, J. Phys. Chem. B., 2009, 113, 11314.

26 B. Ramakrishnan, V. Ramasamy and P. K. Qasba, J. Mol. Biol., 2006, 357, 1619.

27 A. Ochocinska, A. Siegbahn and U. Ellervik, Tetrahedron Lett., 2010, 51, 5200.

28 S. C. Hung, S. R. Thopate and R. Puranik, Carbohydr. Res., 2001, 331, 369.

29 A. Debruyn, M. J. Anteunis, G. Aerts and E. Saman, Carbohydr. Res., 1975, 41, 290.

30 K. Stott, J. Keeler, Q. N. Van and A. J. Shaka, J. Magn. Reson., 1997, 125, 302.

31 R. Wasylishen and T. Schaefer, Can. J. Chem., 1973, 51, 961. 32 R. Aydin and H. Gunther, Magn. Reson. Chem., 1990, 28, 448.

33 J. E. Anderson and A. I. Ijeh, J. Chem. Soc., Perkin Trans. 2, 1994, 1965.

34 T. Nishida, G. Widmalm and P. Sandor, Magn. Reson. Chem., 1995, 33, 596.

35 T. Nishida, G. Widmalm and P. Sandor, Magn. Reson. Chem., 1996, 34, 377.

36 F. del Río-Portilla, E. Sánchez-Mendoza, V. U. ConstantinoCastillo and J. A. del Río, ARKIVOC, 2003, (xi), 213.

37 P.-E. Jansson, J. Lindberg and G. Widmalm, Acta Chem. Scand., 1993, 47, 711.

38 J. F. Stoddard, Stereochemistry of Carbohydrates, John Wiley and Sons, New York, 1971.

39 A. Canales, J. Angulo, R. Ojeda, M. Bruix, R. Fayos, R. Lozano, G. Gimenez-Gallego, M. Martin-Lomas, P. M. Nieto and J. Jimenez-Barbero, J. Am. Chem. Soc., 2005, 127, 5778.

40 I. Talhaoui, C. Bui, R. Oriol, G. Mulliert, S. Gulberti, P. Netter, M. W. H. Coughtrie, M. Ouzzine and S. FournelGigleux, J. Biol. Chem., 2010, 285, 37342.

41 J. F. Garcia-Garcia, G. Corrales, J. Casas, A. FernandezMayoralas and E. Garcia-Junceda, Mol. Biosyst., 2011, 7, 1312.

42 F. Daligault, S. Rahuel-Clermont, S. Gulberti, M. T. Cung, G. Branlant, P. Netter, J. Magdalou and V. Lattard, Biochem. J., 2009, 418, 605. 